http://jmscr.igmpublication.org/home/ ISSN (e)-2347-176x ISSN (p) 2455-0450 crossref DOI: https://dx.doi.org/10.18535/jmscr/v9i10.23

\title{
The Impact of Online Classes on Ocular Health in School Children during the COVID-19 Pandemic
}

\author{
Author \\ Dr Rekha.R.S \\ Assistant Professor, Department of Ophthalmology Sree Gokulam Medical College and Research \\ Foundation Thiruvananthapuram Kerala, India
}

\begin{abstract}
Purpose: The purpose of this study was to estimate the prevalence of Digital Eyestrain (DES), the common symptoms, and the prevalence of each symptom among students attending online classes of standards 6 to 12 during the COVID-19 pandemic and to determine the risk factors associated with it. Methods: This was a cross sectional study conducted in school children from standards 6 to 12 using an online self-administered Google form. Various aspects of digital device use like the type of device used, duration and purpose as well as the presence or absence of the symptoms of DES were included in the questionnaire.

Results: A total of 262 students participated in the study, the mean age of which was $13.51 \pm 2.11$ years. The most common digital device used was smartphone for online classes (89.31\%), doing homework (89.69\%) and for other purposes (60.31\%). The mean duration of online classes per day increased from class 6 (114.82 \pm 39.31 minutes) to class 12 (213.33 \pm 74.52 minutes). The total screen time per day was significantly higher in class 11 (404.21 \pm 102.38 minutes) and 12 (469.58 \pm 142.60 minutes) compared to the lower grades.

The overall prevalence of DES in this study was $69.08 \%$ (95\% CI:63.25,74.37), which increased from $39.02 \%$ in class 6 to $100 \%$ in classes 11 and 12. The prevalence was $94.78 \%$ if used for $>5$ hours /day ( $p$ value $<0.001)$. The most common symptom was eyestrain/ eye pain $(45.8 \%)$ followed by headache (37.79\%). The mean total screen time (358.99 \pm 112.47 minutes) was significantly higher in persons with DES (one way ANOVA test $p<0.001)$ than those without DES $(213.52 \pm 77.88$ minutes).

Conclusion: The prevalence of DES in school children during the COVID-19 era is very high with an alarmingly higher prevalence in the higher grades of classes which can have long term implications. Significant public health awareness and policies are required to save the eyes of the younger generation.
\end{abstract}

\section{Introduction}

It is well known that prolonged digital screen time is detrimental to eye health. This so called "Computer Vision Syndrome" (CVS) is becoming a major public health problem with the increasing use of computers in various professions ${ }^{(1)}$.The term "Digital Eye Strain" (DES), has now replaced the term CVS and it is a group of eye and vision related problems that result from prolonged use of digital devices ${ }^{(1)}$. It encompasses a constellation of ocular symptoms like headache, watering, dry eyes, eye ache, visual blurring, and burning sensation. It is also called by other names such as occupational asthenopia, digital 
asthenopia and video display terminal syndrome(VDTS) $)^{(2,3)}$.

There has been a shift in the education system from classroom learning to e- learning since the COVID-19 lockdown in India as part of the protective measures since $24^{\text {th }}$ of March $2020^{(4)}$. This has led to an alarming rise in the prevalence of DES symptoms in children as well ${ }^{(5)}$. Several studies have reported on the association between screen time especially computers and ocular morbidity in adults ${ }^{(3,6-8)}$, but very few studies have explored the same issue in children ${ }^{(5,9,10)}$. Children are likely to be at higher risk for DES during the COVID-19 pandemic as most of the elearning is through smartphones rather than computers and screen time is also higher as screens have replaced physical class environments.

Hence, a cross sectional study was designed to determine the association of the use of digital platforms and ocular morbidity in children attending online classes from classes 6 to 12 in a district in southern India.

\section{Materials and Methods}

This was a cross sectional study conducted in the general population among school children attending online classes through digital devices from classes 6-12. It was conducted by a tertiary care hospital in a rural area in Southern India. Students below class 6 were not included because it was based on a self- administered Google form which they may not be able to comprehend and give appropriate answers. Children attending classes through television were also not included as television is not considered as a digital device. It was conducted after getting approval from the institutional research board and institutional ethics committee and in accordance with the Declaration of Helsinki.

We estimated a sample size of 235 assuming a prevalence of DES as $50 \%$ ( based on previous studies) and a precision of $5 \%$ and $95 \%$ confidence interval using the formula given below.

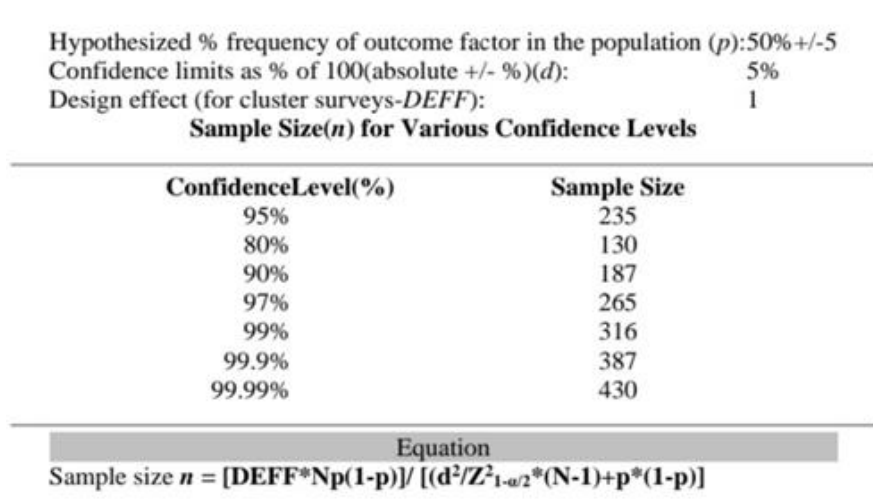

An online questionnaire was prepared using the Google survey forms app. Eligible candidates were selected from the local schools after informing the school authorities and after taking informed consent from the parent / guardian of the child. The online forms were sent to them and the participants were asked to fill the questionnaire themselves after explaining the purpose of the study and reassuring them that the confidentiality and anonymity of the data will be maintained. The questionnaire contained details like age, class, total duration of online class in months, the digital device used, duration of class per day, duration of breaks if any between the classes, the use of digital devices to do homework or taking down notes after the class, or for other purposes, the type of device used and their respective durations. The primary outcome variables assessed were the presence or absence of symptoms of DES like headache, eyestrain/eye pain, watering, redness of eyes, dryness, burning sensation and vision problems.

The data was entered into a MS Excel spread sheet and analysed using the STATA statistical software V 14.0(College station, Tx, USA). Continuous data were expressed as mean and standard deviations and categorical data were expressed as proportions. A Fisher's exact test and ANOVA test were used to explore association between variables.

\section{Results}

This study included 262 participants from classes 6 to 12 with a mean age of $13.5 \pm 2.11$ years (range10-19 years). Maximum number of students 
belonged to class $6(n=82,31.3 \%)$, followed by $17.18 \%$ each in classes 7 and $10(n=45)$ (Table 1). The most common digital device used for online

Table (1) Distribution of students

\begin{tabular}{|l|c|}
\hline Class & Number (\%) \\
\hline 6 & $82(31.3)$ \\
\hline 7 & $45(17.18)$ \\
\hline 8 & $26(9.92)$ \\
\hline 9 & $21(8.02)$ \\
\hline 10 & $45(17.18)$ \\
\hline 11 & $19(7.25)$ \\
\hline 12 & $24(9.16)$ \\
\hline
\end{tabular}



Figure 1 Type of device used for online class, homework and other purposes

Mean duration of online class / day increased from class $6 \quad(114.82 \pm 39.31$ minutes $)$ to class $12(213.33 \pm 74.52$ minutes) (table 2). $93.89 \%$ $(n=246)$ students were using these devices after the class for doing homework, assignments or for taking down notes, with smartphone being the most common device used (89.69\%) and computer the least (1.53\%) (Figure 1). The average duration of device used showed a progressive increase from class $6(76.49 \pm 54.54$ minutes) to class $12(176.25 \pm 78.78$ minutes $)$ (Table 2). Most children ( $n=181,69.08 \%)$ were classes was smartphone $(89.31 \%)$, followed by computer (17.56\%) and tablet (11.45\%) (Figure1). 
Table (2) Duration of screen time per day in each class

\begin{tabular}{|l|c|c|c|c|}
\hline Class & $\begin{array}{c}\text { Online class in } \\
\text { minutes (SD) }\end{array}$ & $\begin{array}{c}\text { Duration for } \\
\text { homework in } \\
\text { minutes (SD) }\end{array}$ & $\begin{array}{c}\text { Duration for other } \\
\text { purposes in } \\
\text { minutes (SD) }\end{array}$ & $\begin{array}{c}\text { Total duration in } \\
\text { minutes (SD) }\end{array}$ \\
\hline 6 & $114.82(39.31)$ & $76.49(54.54)$ & $47.25(51.22)$ & $226.76(95.4)$ \\
\hline 7 & $148(33.65)$ & $80.89(69.03)$ & $59.67951 .61)$ & $288.55(67.84)$ \\
\hline 8 & $160.38(45.45)$ & $95.49(56.27)$ & $59.23(45.86)$ & $311.34(94.95)$ \\
\hline 9 & $180.09(41.39)$ & $122.86(35.38)$ & $70(49.60)$ & $372.95(88.20)$ \\
\hline 10 & $184.33(63.13)$ & $136.67953 .34)$ & $30.44(35.29)$ & $351.44(100.49)$ \\
\hline 11 & $201.32(34.91)$ & $143.68(49.58)$ & $59.21(42.85)$ & $404.21(102.38)$ \\
\hline 12 & $213.33(74.52)$ & $176.25(78.78)$ & $80(47.37)$ & $469.58(142.60)$ \\
\hline
\end{tabular}

One hundred and eighty one of 262 participants reported one or more symptoms of DES, which amounted to an overall prevalence of $69.08 \%$ (95\% CI: $63.25,74.37$ ) in this study. The prevalence of DES increased from $39.02 \%$ in class 6 to $100 \%$ in classes 11 and 12 (Table 3). The prevalence of DES did not differ significantly $(\mathrm{p}=0.58)$ by the type of digital device used with a prevalence of $67.89 \%$ in smartphone users, and $62.5 \%$ and $66.67 \%$ in computer users and tablet users respectively, and $77.27 \%$ in children using more than one device.

Table (3) Prevalence of DES in each class

\begin{tabular}{|l|c|}
\hline Class & Prevalence in number $(\%)$ \\
\hline 6 & $32(39.02 \%)$ \\
\hline 7 & $25(55.56 \%)$ \\
\hline 8 & $21(80.77 \%)$ \\
\hline 9 & $19(90.48 \%)$ \\
\hline 10 & $41(91.11 \%)$ \\
\hline 11 & $19(100 \%)$ \\
\hline 12 & $24(100 \%)$ \\
\hline
\end{tabular}

The most common symptom was eyestrain / eye pain which was reported by 120 participants $(45.8 \%)$ followed by headache which was reported by 99 (37.79\%) (Table4). Redness of eyes were the least reported symptom (11.83\%). $18.46 \% \quad(\mathrm{n}=48)$ participants had only one symptom of DES, $18.85 \% \quad(n=49)$ had two symptoms, while $31.54 \% \quad(n=82)$ had three or more symptoms of DES.

Table (4) Symptoms of DES

\begin{tabular}{|l|l|}
\hline Symptom & Number (\%) \\
\hline Eyestrain /pain & $120(45.8 \%)$ \\
\hline Headache & $99(37.79 \%)$ \\
\hline Burning sensation & $76(29.01 \%)$ \\
\hline Redness vision problems & $60(22.90 \%)$ \\
\hline Watering & $46(17.56 \%)$ \\
\hline Dryness & $40(15.27 \%)$ \\
\hline Redness & $31(11.83 \%)$ \\
\hline
\end{tabular}

On analysing the relationship between the daily total duration of use of digital device and the prevalence of DES, it was found that prevalence was $0 \%$ if used for $<1$ hour/ day which increased to $94.78 \%$ if used for $>5$ hours/ day with a $\mathrm{p}$ value of $<0.001$ (Table 5). The mean total duration of device use (358.99 \pm 112.47 minutes) was significantly higher (one way ANOVA test $p$ $<0.001)$ in persons with DES compared to persons without DES (213.52 \pm 77.88 minutes).

Table (5) Relationship between total screen time / day and DES

\begin{tabular}{|l|c|}
\hline $\begin{array}{l}\text { Total screen time / } \\
\text { day (hours) }\end{array}$ & Prevalence of DES (\%) \\
\hline$\leq 1 \mathrm{hr}$ & 0 \\
\hline$>1 \mathrm{hr}-\leq 2 \mathrm{hrs}$ & 27.78 \\
\hline$>2 \mathrm{hrs}-\leq 3 \mathrm{hrs}$ & 16.67 \\
\hline$>3 \mathrm{hrs}-\leq 4 \mathrm{hrs}$ & 53.19 \\
\hline$>4 \mathrm{hrs}-\leq 5 \mathrm{hrs}$ & 52.63 \\
\hline$>5 \mathrm{hrs}$ & 94.78 \\
\hline
\end{tabular}

\section{Discussion}

With the advent of the COVID-19 pandemic, there has been a sudden surge in the rate of digital device users worldwide including $\operatorname{India}^{(11,12)}$. This has affected the ocular health of adults as well as younger children ${ }^{(5,9,11,13)}$. Previously these devices were used by children primarily for entertainment purposes. But with the shifting of educational system to e-learning, which is an inevitable necessity during this pandemic, there has been a marked rise in their use among this group also.

Very few studies have estimated the prevalence of DES among children during the pandemic. Literature search showed that there is only one similar study conducted in India done by Amit Mohan et al in Madhya Pradesh ${ }^{(5)}$. The mean age 
of our cohort was $13.51 \pm 2.11$ years which was very similar to their study in which the mean age was $13 \pm 2.45$ years.

In this study the most common device used for online classes was smartphone ( $89.31 \%$ ), which was higher than that found in the study by Amit Mohan et al $(61.7 \%)^{(5)}$. Only very few children were using computers $(17.56 \%)$ and tablets $(11.45 \%)$. The same pattern was seen for doing homework or assignments and for other purposes (89.69\% and $60.31 \%$ were using smartphones respectively). The higher use of smartphones may be attributed to the fact that the study was conducted in a rural setting where smartphones were more affordable than computers and tablets.

Several studies conducted previously in adult population in different countries have showed that the prevalence of DES varies from $25 \%$ to $93 \%$ depending on the population studied and the methodologies used ${ }^{(5)}$. In this study the prevalence in the 6-12 graders was $69.08 \%$ which was higher than that that done by Amit Mohan et al $(50.23 \%)^{(5)}$ in the same age group and another done by Ganne et al on students above 18 years in Bangalore $(50.6 \%)^{(9)}$ during the COVID era. But it was very close to the prevalence reported in the 2016 DES report done on 10,000 US adult population which was $65 \%{ }^{(14)}$.

Several studies done previously have reported that the prevalence of DES is directly proportional to the screen time $(9,15)$. In this study it was found that the DES prevalence was $0 \%$ among children with a screen time $<1$ hour per day, whereas it increased significantly with a prevalence of $52.63 \%$ if used for $>4$ hours/day and to $94.78 \%$ if used for $>5$ hours /day. A similar finding was reported by another study done by Ichhpujani P et al in school children where the DES prevalence was significantly higher in the>4hours/day group $^{(16)}$. The time spent for online classes was significantly higher in higher grades compared to the lower grades ( $213.33 \pm 74.52$ minutes in grade 12 vs $114.82 \pm 39.31$ minutes in grade 6) which was reported by Amit Mohan et al ${ }^{(5)}$ also. The increased class time and the increased time spent for doing homework, assignments and for other purposes in the higher grades especially in grades 11 and 12 ( total time spent was 404.21 \pm 102.38 minutes in class 11 and $469.58 \pm 142.60$ minutes in class 12) resulted in $100 \%$ DES prevalence in this group. The increased screen time in this group may be attributed to the time spent for online tuitions and entrance classes. This is the first report of its kind analysing the prevalence of DES in different grades of classes. In another study conducted by Moon $\mathrm{J} \mathrm{H}$ et al on the relationship between DES and age, it was reported that older children had more screen time leading to a higher prevalence of DES in older children ${ }^{(17)}$

DES was significantly higher in those using smartphones than other devices in a study conducted by Mohammed Iqbal et $\mathrm{al}^{(18)}$ on medical students in Egypt .Sheppard et al ${ }^{(14)}$ had reported that the prevalence of DES is more in individuals who use more than one device simultaneously, compared with those using a single device (75\% and 53\% respectively). But there was no statistically significant difference in the prevalence of DES between the groups using different devices or between those using single vs multiple devices in our study. Our results are similar to that reported by Ganne et $\mathrm{al}^{(9)}$ who reported that it was the total screen time which was significant irrespective of the device used.

According to the American Optometric Association, the most common symptoms associated with DES are eyestrain, headache, blurred vision, dry eyes, burning sensation, watering, irritation and photophobia ${ }^{(19)}$. Increased screen time causes a decrease in the blink rate ${ }^{(20-}$ 22) leading to evaporation of tear film and improper distribution of the tears leading to symptoms like dryness, burning sensation, foreign body sensation, photophobia and itching. Constant near viewing also leads to an increased demand on the accommodation and convergence systems of the eyes leading to eyestrain, eye pain, headache, difficulty in refocusing and diplopia $^{(14,23)}$. The most common symptom in our study was eyestrain/ eye pain which was reported 
by $45.8 \%$ followed by headache reported by 37.79 $\%$. This was unlike most other studies where headache was the most prominent symptom $^{(5,7,8,15,18,24)}$. The difference may be attributable to differences in the study population as most of the other studies were done on adult population where prevalence of migraine and other vascular headaches are more prevalent and increased screen time could have aggravated those headaches. Another prominent symptom was visual blurring reported by $22.9 \%$ participants. This needs urgent attention because a metaanalysis done by Holden et alhad predicted a two fold increase in the prevalence of myopia and a seven fold increase in the visual loss by myopia by $2020^{(25)}$. The increased screen time during the lockdown along with the restrictions of outdoor activities of children and lack of sunlight exposure due to the pandemic might aggravate this progression. Recently, Jayadevan et al had expressed concern that these factors might lead to an explosive condition called "quarantine myopia" post COVID-19 pandemic ${ }^{(11)}$. A previous study by Al Rashidi et al on medical students in Saudi Arabia, had found a statistically significant association between myopia and the severity of DES.(13).31.54\% of the participants had 3 or more symptoms of DES.

We did not find a significant association between the duration of breaks and the prevalence of DES which is consistent with previous studies by Reddy et $\mathrm{al}^{(26)}$ and Mowatt et $\mathrm{al}^{(27)}$. The lack of association might be because children did not understand the purpose of giving breaks and continued to use these devices even during the breaks.

A limitation of the study is that the study utilised a self- administered questionnaire without any ophthalmological evaluation or refraction testing to confirm DES. There is a chance that the children may have under or over reported symptoms. Previous studies have shown that preexisting refractive errors can aggravate $\operatorname{DES}^{(9,14)}$. We have not considered the duration of television viewing in this study which also can aggravate
DES. The ergonomic practices followed like adjustments for brightness of the screen, distance of viewing, surrounding illumination or position of screens were also not assessed.

\section{Conclusion}

This study highlights the importance of a serious health issue called Digital Eyestrain (DES) growing rapidly in the current situation of COVID-19 pandemic especially in the younger population which can have significant long term effects. There is an urgent need to create awareness among all the stakeholders about this problem and make policies to ameliorate this.

\section{References}

1. Randolph SA. Computer Vision Syndrome. Workplace Health Saf. 2017 Jul;65(7):328.

2. Chawla A, Lim TC, Shikhare SN, Munk PL, Peh WCG. Computer Vision Syndrome: Darkness Under the Shadow of Light. Can Assoc Radiol J. 2019 Feb;70(1):5-9.

3. Parihar JKS, Jain VK, Chaturvedi P, Kaushik J, Jain G, Parihar AKS. Computer and visual display terminals (VDT) vision syndrome (CVDTS). Med J Armed Forces India. $2016 \mathrm{Jul} ; 72(3): 270-6$.

4. COVID-19 lockdown in India. In: Wikipedia [Internet]. 2021 [cited 2021 Apr 29]. Available from: https://en.wikipedia.org/w/index.php?title= COVID-

19_lockdown_in_India\&oldid=102009996 3

5. Mohan A, Sen P, Shah C, Jain E, Jain S. Prevalence and risk factor assessment of digital eye strain among children using online e-learning during the COVID-19 pandemic: Digital eye strain among kids (DESK study-1). Indian J Ophthalmol. 2021 Jan;69(1):140-4.

6. Shantakumari N, Eldeeb R, Sreedharan J, Gopal K. Computer use and vision-related 
problems among university students in ajman, United arab emirate. Ann Med Health Sci Res. 2014 Mar;4(2):258-63.

7. Ranasinghe $P$, Wathurapatha WS, Perera YS, Lamabadusuriya DA, Kulatunga S, Jayawardana $\mathrm{N}$, et al. Computer vision syndrome among computer office workers in a developing country: an evaluation of prevalence and risk factors. BMC Res Notes. 2016 Mar 9;9:150.

8. Altalhi A, Khayyat W, Khojah O, Alsalmi $\mathrm{M}$, Almarzouki H. Computer Vision Syndrome Among Health Sciences Students in Saudi Arabia: Prevalence and Risk Factors. Cureus. 2020 Feb 20;12(2):e7060.

9. Ganne P, Najeeb S, Chaitanya G, Sharma A, Krishnappa NC. Digital Eye Strain Epidemic amid COVID-19 Pandemic - A Cross-sectional Survey. Ophthalmic Epidemiol. 2020 Dec 28;1-8.

10. Veselý P, Hanák L, Beneš P. Digital Eye Strain in a Population of Young Subjects. Cesk Slov Oftalmol. 2019;74(4):154-7.

11. Jayadev C, Sarbajna P, Vinekar A. Commentary: Impact of the COVID-19 pandemic on digital eye strain in children. Indian Journal of Ophthalmology. 2020 Nov;68(11):2383-4.

12. Tawonkasiwattanakun $P$, Tonkerdmongkol D, Poyomtip T. To save our eyes, urgent public health policies are required after the COVID-19 pandemic. Public Health. 2021 Mar 4;

13. Wong CW, Tsai A, Jonas JB, OhnoMatsui K, Chen J, Ang M, et al. Digital Screen Time During the COVID-19 Pandemic: Risk for a Further Myopia Boom? Am J Ophthalmol. 2021 Mar;223:333-7.

14. Sheppard AL, Wolffsohn JS. Digital eye strain: prevalence, measurement and amelioration. BMJ Open Ophthalmol. 2018;3(1):e000146.
15. Al Tawil L, Aldokhayel S, Zeitouni L, Qadoumi T, Hussein S, Ahamed SS. Prevalence of self-reported computer vision syndrome symptoms and its associated factors among university students. Eur J Ophthalmol. 2020 Jan;30(1):189-95.

16. Ichhpujani P, Singh RB, Foulsham W, Thakur S, Lamba AS. Visual implications of digital device usage in school children: a cross-sectional study. BMC Ophthalmol. 2019 Mar 12;19(1):76.

17. Moon JH, Lee MY, Moon NJ. Association between video display terminal use and dry eye disease in school children. J Pediatr Ophthalmol Strabismus. 2014 Apr;51(2):87-92.

18. Iqbal M, Said O, Ibrahim O, Soliman A. Visual Sequelae of Computer Vision Syndrome: A Cross-Sectional CaseControl Study. J Ophthalmol. 2021;2021: 6630286.

19. Computer vision syndrome (Digital eye strain) [Internet]. [cited 2021 Apr 29]. Available from: https://www.aoa.org/healthy-eyes/eye-andvision-conditions/computer-visionsyndrome? sso=y

20. Patel S, Henderson R, Bradley L, Galloway B, Hunter L. Effect of visual display unit use on blink rate and tear stability. Optom Vis Sci. 1991 Nov;68(11):888-92.

21. Freudenthaler N, Neuf H, Kadner G, Schlote T. Characteristics of spontaneous eyeblink activity during video display terminal use in healthy volunteers. Graefes Arch Clin Exp Ophthalmol. 2003 Nov;241(11):914-20.

22. Hirota M, Uozato $H$, Kawamorita $T$, Shibata Y, Yamamoto S. Effect of incomplete blinking on tear film stability. Optom Vis Sci. 2013 Jul;90(7):650-7.

23. Bhootra AK. Basics of Computer Vision Syndrome [Internet]. jaypee; 2014 [cited 
2021 Apr 29]. Available from: https://www.jaypeedigital.com/book/9789 351524137

24. Bahkir FA, Grandee SS. Impact of the COVID-19 lockdown on digital devicerelated ocular health. Indian J Ophthalmol. 2020 Nov;68(11):2378-83.

25. Holden BA, Fricke TR, Wilson DA, Jong M, Naidoo KS, Sankaridurg P, et al. Global Prevalence of Myopia and High Myopia and Temporal Trends from 2000 through 2050. Ophthalmology. 2016 May;123(5):1036-42.

26. Reddy SC, Low CK, Lim YP, Low LL, Mardina F, Nursaleha MP. Computer vision syndrome: a study of knowledge and practices in university students. Nepal J Ophthalmol. 2013 Dec;5(2):161-8.

27. Mowatt L, Gordon C, Santosh ABR, Jones T. Computer vision syndrome and ergonomic practices among undergraduate university students. Int J Clin Pract. 2018 Jan;72(1). 